\title{
Configuration and Evaluation on Gas-fueled Distributed Energy System Used in hotel Building
}

\author{
Lei Zhao \\ Jilin Jianzhu University, Changchun, Jilin, China \\ Zhao0438@126.com
}

Keywords: Natural Gas , Distributed Energy , System Configuration , Evaluation Indexes

\begin{abstract}
In this paper, characteristics of distributed energy system powered by gas turbine and gas-fueled internal combustion engine are analyzed. System configuration scheme was designed based on meteorological condition, internal load demand and time of equipment utilization. Compared with conventional energy system, distributed energy system can generate better energy-saving, economic and environmental protection benefit.
\end{abstract}

\section{Introduction}

Demand on energy has been increasing with the growth of economy, for which firstly, energy should be utilized in an efficient way, and then environmental issues caused by utilization of energy should also be solved. In the traditional way of energy supply, various loads including cooling, heating and power load are separately supplied to a building, and such a system has some disadvantages. In a power generation system, a part of heat released by combustion of fossil fuel is transformed into electricity by a heat engine, and the rest is transmitted into the environment. Heat provided by boilers in the heat supply system to users accounts for $70 \%$ to $90 \%$ of the heat released by combustion of fuel, and high-temperature smoke and gas generated by combustion of fuel are used to heat up steam or hot water at a lower temperature, during which loss of work is significant. Utilization of absorption refrigerator in the cooling system is restricted due to some issues such as that the equipment is far from the heat source or long-distance transmission of cooling capacity cannot be realized. Even for gas-fueled and direct-fired absorption refrigerator, there exists a certain degree of work loss similar to the situation with boilers. Meanwhile, power plants need to improve their production capacity because of peak load caused by use of air conditioners in summer, which will generate a large amount of surplus heat that cannot be utilized and thus result in a significant waste of energy ${ }^{[1]}$.

Gas-fueled distributed energy system is a system combining power generation, refrigeration and heat supply, which can improve the efficiency of energy utilization significantly. Regional and building-based combined cooling, heating and power system are major types of such system, in which the latter is mainly used in public buildings such as office building, hotel, store and hospital. The analysis on hotel buildings is conducted in this paper.

\section{Gas-fueled Distributed Energy System}

A distributed energy system can be divided into three sub-systems, including power system (power generation), heating system (supply of heat, hot water, etc.) and refrigerating system (refrigeration, dehumidification, etc.).

Power generation equipment in the power system is the core equipment in a distributed energy system, which now mainly include: Gas turbine, internal combustion engine, micro-gas turbine, Stirling engine and fuel cell. Among them, gas turbine and internal combustion engine are the most widely used two types of power generation systems, for which relevant technology is quite mature. System flow of distributed energy system powered by gas turbine used in hotel building is indicated in Figure 1.

Natural gas is combusted in gas turbine, which can output mechanical work to be used by the generating set to generate power. When quantity of generated electricity is insufficient, the shortage can be covered by purchasing electricity from power grid. As for buildings with no demand on thermal 
load, high-temperature smoke and gas discharged by gas turbine after power generation enter into exhaust-heat boiler for steam generation. Heat exchanges between steam and water happens in heat exchanger, after which hot water enters into lithium bromide-absorption refrigerator, which will be used for refrigeration in summer and heat supply in winter. When refrigerating capacity cannot fully meet users' demand, the shortage can be covered by electrical refrigeration. When exhaust-heat boiler cannot supply enough heat, after burning can be adopted to make up for any shortage.

Different from the situation with gas turbine, recovery of waste heat for internal combustion engine includes two parts, namely recovery of waste heat from cooling water and hot smoke and gas, for which flow chart is indicated in Figure 2. Users' demand on electric power can be met by electricity generated by internal combustion engine and purchased from power grid, and their demand on refrigerating capacity can be supplied by absorption cooling and heating unit based on smoke and hot water as well as electrical refrigerating unit. As for buildings with demand on heat load, absorption cooling and heating unit based on smoke and hot water can be used to supply heat to users, and shortage of heat can be covered by heat supplied by hot-water boiler.

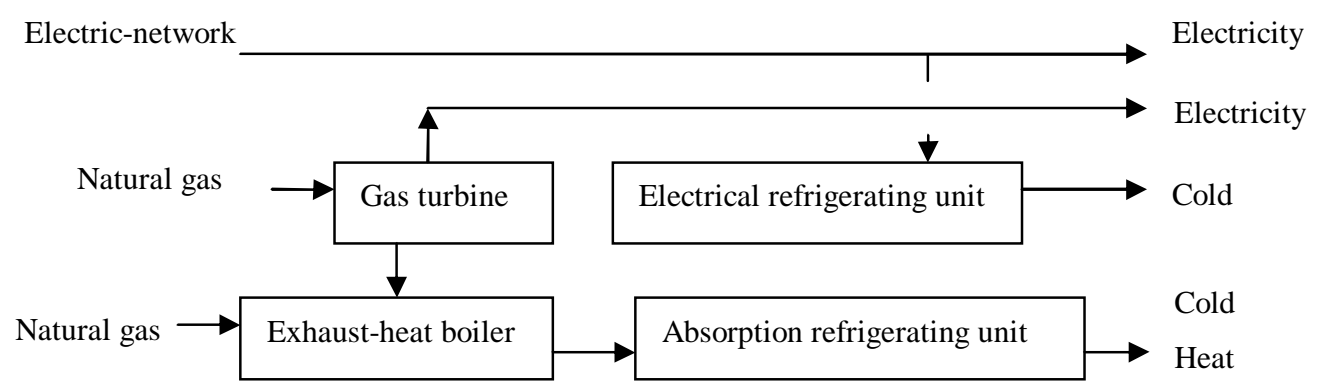

Figure 1 Distributed Energy System Powered by Gas Turbine

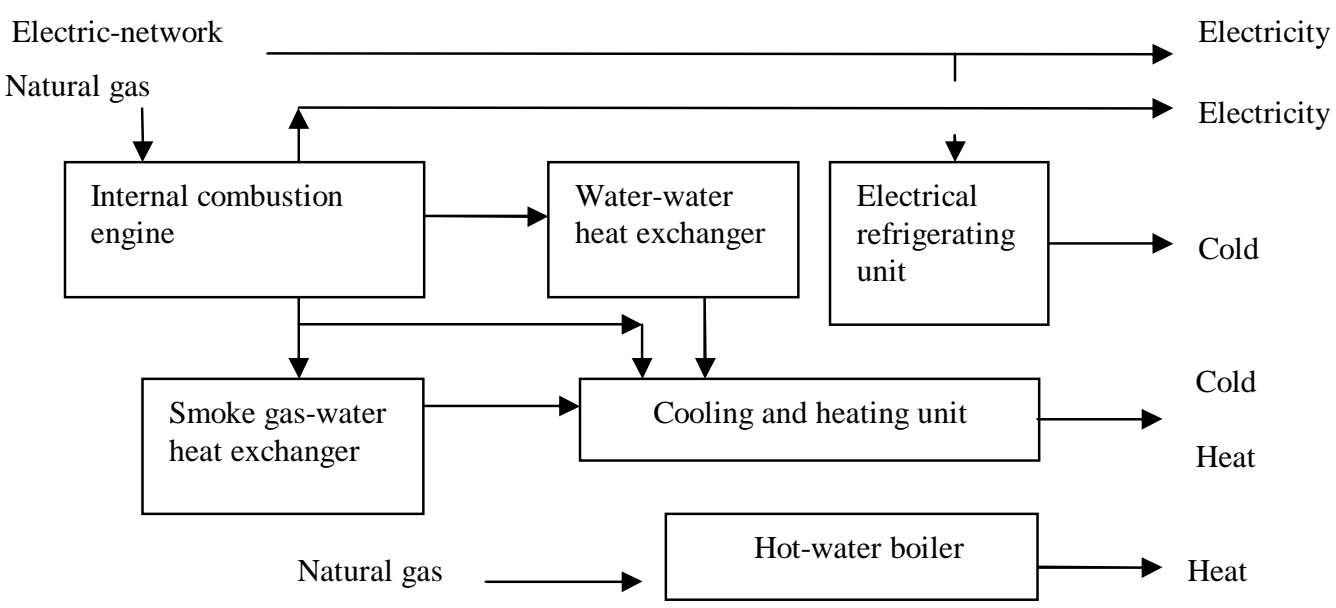

Figure 2 Distributed Energy System Powered by Internal Combustion Engine

\section{System Configuration Scheme on the hotel Building}

An hotel building located in Changchun City, Jilin Province is simulated in this paper, for which total building area is $321260 \mathrm{~m}^{2}$; area covered by air conditioning totals $245321 \mathrm{~m}^{2}$, and there are 18 floors in total. The hotel does business in the whole annual. Municipal conditions around the office building: The city's heat supply network can supply heat to the office building in winter; there are medium-pressure gas pipeline around the building, for which heating through combustion of coal is not allowed.

Cooling, heating and power load in the building can be obtained through load simulation program. In practical application of distributed combined cooling, heating and power supply system, the practice of determining heat based on electricity is generally adopted, for which shortage of power should be 
covered with electricity purchased from power grid; shortage of refrigerating capacity should be covered by electrical refrigerator; and shortage of heat should be covered by after burning of boiler. The way of connecting to power grid but not transmitting electricity to it is adopted in power system. System configuration scheme should be designed based on some characteristics such as meteorological condition of Changchun City, internal demand on load of the hotel building and period of equipment utilization. Configuration scheme for distributed power equipment powered by internal combustion engine is indicated in Table 1.

Table 1 Configuration Scheme for Distributed Energy Equipment Powered

\begin{tabular}{|c|c|c|}
\hline Name of Equipment & $\begin{array}{c}\text { Rated Power } \\
\text { KW }\end{array}$ & $\begin{array}{c}\text { Quantity } \\
\text { Set }\end{array}$ \\
\hline Generator & 500 & 2 \\
\hline $\begin{array}{c}\text { Cooling/ } \\
\text { Heating Unit }\end{array}$ & $\begin{array}{c}\text { Heating: } 1065 \\
\text { Refrigeration: } 835\end{array}$ & 1 \\
\hline Hot-water Boiler & 825 & 2 \\
\hline Electrical Refrigerator & 660 & 2 \\
\hline
\end{tabular}

\section{Compared with conventional energy system and distributed energy system}

For conventional energy system, the power is purchased from power grid, the cooling load is provided by electric refrigeration unit, the required heat load is provided by gas boiler.

In this paper, configuration scheme for distributed energy system used in office building is evaluated from three perspectives including energy saving, economy and environmental protection.

Evaluation Indexes. Primary energy utilization ratio is used for evaluating on energy-saving performance of distributed energy system. Annual rate of operation cost saving and payback period of incremental investment are used as evaluation indexes. Annual emission reduction rate for $\mathrm{CO}_{2}$ and $\mathrm{NO}_{\mathrm{X}}$ are selected to evaluate the performance of distributed energy system in environmental protection $^{[2]}$.

Formula for calculation of primary energy utilization ratio is Eq. 1 .Formula for calculation of annualrate of operation cost saving is Eq. 2. Formula for calculation of payback period of incremental investment is Eq. 3. Formula for calculation of annual emission reduction rate for $\mathrm{CO}_{2}$ is Eq. 4 . Formula for calculation of annual emission reduction rate for $\mathrm{NO}_{\mathrm{X}}$ is $\mathrm{Eq} .5$

$$
\begin{aligned}
& P E R=\left(E+Q_{c}+Q_{h}\right) /\left(G+E_{e} / \eta_{1} \eta_{2}\right) \\
& I_{1}=\left(C_{1}-C\right) / C_{1} \\
& \Delta N=\Delta Z /\left(S_{1}-S\right) \\
& R_{C O_{2}}=\left(P_{1, C_{2}}-P_{C O_{2}}\right) / P_{1, C O_{2}} \\
& R_{N O_{x}}=\left(P_{1, N O_{x}}-P_{N O_{x}}\right) / P_{1, N O_{x}}
\end{aligned}
$$

In the formula, $E$ is the total amount of electricity outputted by the system during the period (Unit: $\mathrm{kW}), Q_{c}$ is the total refrigerating capacity outputted by the system during the period (Unit: $\mathrm{kW}$ ), $Q_{h}$ is the total heat outputted by the system during the period (Unit: $\mathrm{kW}$ ), $G$ is the amount of heat generated by the system during the pe- riod through combustion of natural gas (Unit: $\mathrm{kW}$ ), $E_{e}$ is the amount of electricity purchased from public power grid by the system during the period (Unit: $\mathrm{kW}$ ), $\eta_{1}$ is generating efficiency of the power plant, $\eta_{2}$ is the efficiency of power transmission and distribution of the public power grid. $I_{1}$ is annual rate of operation cost saving, $C$ is annual operation cost of 
distributed energy system (Unit: Yuan/year), $C_{1}$ is annual operation cost of conventional separate energy supply system (Unit: Yuan/year). $\Delta N$ is payback period of incremental investment (Unit: Year), $\Delta Z$ is incremental investment of distributed energy system compared to conventional separate energy supply system (Unit: Yuan), $S_{1}$ is annual cost of energy consumption and equipment maintenance cost of separate energy supply system, $S$ is annual cost of energy consumption and equipment maintenance cost of distributed energy system. $R_{\mathrm{CO} 2}$ is annual emission reduction rate for $\mathrm{CO}_{2}, P_{\mathrm{CO} 2}$ is the annual amount of $\mathrm{CO}_{2}$ discharged by conventional separate energy supply system (Unit: $\mathrm{t} / \mathrm{year}$ ), $P_{1, \mathrm{CO} 2}$ is the annual amount of $\mathrm{CO}_{2}$ discharged by distributed energy system (Unit: $\mathrm{t} / \mathrm{year}$ ). $R_{N O x}$ is annual emission reduction rate for NOx, $P_{N O x}$ is the annual amount of NOx discharged by conventional separate energy supply system (Unit: $\mathrm{t} / \mathrm{year}$ ), $P_{1, N O x}$ is the annual amount of NOx discharged by distributed energy system (Unit: t/year).

Evaluation Result. Evaluation indexes of the hotel building are indicated in Table 2. Commercial electricity price adopted in Changchun City, namely 0.89 Yuan/kWh, is used in the table as electricity price, and price of natural gas is $3.92 \mathrm{Yuan} / \mathrm{m}^{3}$ and lower calorific value is $35.7 \mathrm{MJ} / \mathrm{Nm}^{3}$. Performance parameters, initial investment and maintenance cost of various equipments are obtained through survey on equipment manufacturers and study on relevant data in documents and literatures.

Table 2. Result of Evaluation on The Hotel Building

\begin{tabular}{|c|c|c|c|c|}
\hline PER & $\mathrm{I}_{1}$ & $\Delta \mathrm{N}$ & $\mathrm{R}_{\mathrm{CO} 2}$ & $\mathrm{R}_{\text {Nox }}$ \\
\hline $82.5 \%$ & $17.6 \%$ & 2.78 & $40 \%$ & $65 \%$ \\
\hline
\end{tabular}

\section{Conclusion}

As for distributed energy system used in hotel buildings, primary energy utilization rate in summer and winter is relatively high, and that in transitional seasons is relatively low, the reason of which is that cooling and heating load in transitional seasons are relatively low, and waste heat released by distributed energy system cannot be utilized and thus directly discharged into the atmosphere. During its operation in various seasons in a year, distributed energy system is more energy-saving than conventional separate energy supply system, which can generate better energy-saving benefit.

Compared with conventional separate energy supply system, distributed energy system used in hotel building requires higher annual equivalent cost for initial investment and maintenance cost. However, based on given price of electricity and gas, annual cost of energy consumption for operation of distributed energy system is lower than that of separate energy supply system. As for distributed energy system, payback period for incremental investment is relatively short and it thus can generate more economic benefit.

Distributed energy system can reduce the emission of some pollutants including $\mathrm{CO}_{2}$ and $\mathrm{NO}_{\mathrm{X}}$ to a large extent, so such system used in hotel building can generate more environmental protection benefit.

\section{References}

[1] Mingqing Yan, Design Manual for Gas Engineering, China Architecture \& Building Press, Beijing , 2009

[2] Lin Fu and Hui Li , Combined Cooling, Heating and Power Supply Technology and Its Application , China Architecture \& Building Press, Beijing , 2008 